\title{
Cyclosporin A Protects H9c2 Cells Against Chemical Hypoxia-Induced Injury via Inhibition of MAPK Signaling Pathway
}

\author{
Gang WANG, ${ }^{1} \mathrm{MD}$, Jie CUI, ${ }^{2} \mathrm{MD}$, Yifeng GuO, ${ }^{3} \mathrm{MD}$, Yueqiang WANG, ${ }^{1} \mathrm{MD}$, \\ Ling KANG, ${ }^{1} \mathrm{MD}$, and Libo LIU, ${ }^{1} \mathrm{MD}$
}

\begin{abstract}
SUMMARY
This study aimed to investigate the effects and molecular mechanism of cyclosporin A (CsA) on cobalt chloride $\left(\mathrm{CoCl}_{2}\right)$-induced injury in $\mathrm{H} 9 \mathrm{c} 2$ embryonic rat cardiac cells. The results showed that $\mathrm{CsA}$ could protect $\mathrm{H} 9 \mathrm{c} 2$ cells against $\mathrm{CoCl}_{2}$-induced hypoxic injury. CsA effectively improved cell viability, and decreased LDH leakage, cell apoptosis, MDA concentration, and ROS generation, and increased SOD activity, GSH production, and CAT activity in a dosedependent manner. In addition, CsA treatment blocked the $\mathrm{CoCl}_{2}$-induced increases in ROS production and mitochondrial dysfunction, including a decrease in membrane potential, cytochrome $c$ (cyto-c) release, Bax/Bcl-2 imbalance, as well as the ratios of cl-casp-9/casp-9 and cl-casp-3/casp-3 ratios, via the inhibition of p38 and ERK MAPK signaling pathways. The results also suggested that $\mathrm{CsA}$ protected $\mathrm{H} 9 \mathrm{c} 2$ cells against $\mathrm{CoCl}_{2}$-induced hypoxic injury, possibly by suppressing the MAPK signaling pathway. Thus, CsA is a potential therapeutic agent for cardiac hypoxic injury. (Int Heart J 2016; 57: 483-489)
\end{abstract}

Key words: $\mathrm{CoCl}_{2}$

$\mathrm{C}$ closporin A (CsA) is a powerful immunosuppressive drug. Recent evidence indicates that CsA may serve as an important biological cytoprotective agent. CsA has been reported to be a multifactorial neuroprotective agent that putatively exerts neuroprotective and neurotrophic effects on traumatic brain injury and sciatic nerve injuries, as well as focal and global ischemia. ${ }^{1)}$ However, the cardioprotective effects of CsA are still unknown.

Such cytoprotection is associated with the suppression of myocardial oxidative stress and preservation of mitochondrial structure and function. ${ }^{2)}$ The oxidative stress injury caused by cardiac ischemia/reperfusion injury has been attributed to the activation of mitogen activated protein kinase (MAPK) pathways, including the p38, extracellular signal-regulated kinase (ERK), and c-Jun N-terminal kinase (JNK) pathways. ERK promotes cell survival, whereas JNK and p38 lead to cell death. MAPK plays a pivotal role in cardiovascular diseases and is involved in cell survival and the recovery of damaged myocardial apoptosis. ${ }^{3)}$

Cobalt chloride $\left(\mathrm{CoCl}_{2}\right)$ is a chemical hypoxia mimetic agent. $\mathrm{CoCl}_{2}$ can mimic hypoxic/ischemic conditions, including ROS generation, in various cultured cells. ${ }^{4,5)} \mathrm{H} 9 \mathrm{c} 2$ embryonic rat cardiac cells, a subclone of an original clonal cell line, are derived from rat embryonic hearts and have been used as in vitro models for exploring the mechanisms underlying hypoxia-induced apoptosis of cardiomyocytes. $\left.{ }^{6}\right)$ Therefore, in the present study, we used $\mathrm{CoCl}_{2}$-treated $\mathrm{H} 9 \mathrm{c} 2$ cells as a model with which to investigate whether CsA protects $\mathrm{H} 9 \mathrm{c} 2$ cells from chemical hypoxia-induced injury and reduces oxidative stress and mitochondrial damage by the inhibition of MAPK signaling pathways.

\section{MeTHODS}

Materials: $\mathrm{CsA}$ and $\mathrm{CoCl}_{2}$ were purchased from Sigma. Bax, Bcl-2, cleaved caspase-9, caspase-9, cleaved caspase-3, caspase-3, cyto-c, p-p38, p38, p-ERK1/2, ERK1/2, p-JNK1/2, JNK1/2, and $\beta$-actin were purchased from Cell Signaling Technology (Danvers, MA, USA).

Cell culture and treatment: $\mathrm{H} 9 \mathrm{c} 2$ embryonic rat cardiac cells were purchased from the Chinese Academy of Sciences (Shanghai, China). Briefly, the H9c2 cells were cultured in DMEM-F12 medium supplemented with $20 \% \mathrm{FBS}$ at $37^{\circ} \mathrm{C}$ under an atmosphere of $5 \% \mathrm{CO}_{2}$ and $95 \%$ air.

Chemical hypoxia was achieved by adding $\mathrm{CoCl}_{2}$ at the concentrations indicated into the medium and incubating cells in the presence of $\mathrm{CoCl}_{2}$ for 24 hours. In order to explore the

From the ${ }^{1}$ Department of Cardiology, Affiliated Hospital of Taishan Medical College, Taian, Shandong, ${ }^{2}$ Department of Burn Surgery, Beijing Fengtai You'anmen Hospital, Fengtai, Beijing, and ${ }^{3}$ Department of Clinical Laboratory, People's Hospital of Xintai, Taian, Shandong, China.

This work was supported by Grants from the Scientific Development Plan of Taian (No. 201440771).

Address for correspondence: Gang Wang, MD, Department of Cardiology, Affiliated Hospital of Taishan Medical College, Taishan Street No. 706, Taian, Shandong, China. E-mail: wanggangtyfy@126.com

Received for publication February 19, 2016. Revised and accepted March 25, 2016.

Released in advance online on J-STAGE June 29, 2016.

All rights reserved by the International Heart Journal Association. 
effects of $\mathrm{CsA}$ on $\mathrm{CoCl}_{2}$-induced cell injury, after $\mathrm{CoCl}_{2}$-induced cell injury, $\mathrm{H} 9 \mathrm{c} 2$ cells were maintained in complete medium with $10 \mathrm{ng} / \mathrm{mL}, 30 \mathrm{ng} / \mathrm{mL}$, and $50 \mathrm{ng} / \mathrm{mL}$ CsA or MAPK inhibitors, $15 \mu \mathrm{M}$ SB203580 (Abcam, Cambridge, UK), 15 $\mu \mathrm{M}$ U0126 (Abcam), and $15 \mu \mathrm{M}$ SP600125 (Abcam). The control cells were incubated without $\mathrm{CsA}$ and $\mathrm{CoCl}_{2}$.

Cell viability assay: A Cell Counter Kit-8 (CCK-8) assay was used to investigate the cell viability of $\mathrm{H} 9 \mathrm{c} 2$ cells cultured in 96-well plates at a density of 5000 cells/well. When the cells had grown to $70-80 \%$ confluence, $\mathrm{CoCl}_{2}$-induced cell injury was performed. Therefore, $10 \mu \mathrm{L} \mathrm{CCK}-8$ solution was added to each well and the cells were incubated for a further 4 hours at $37^{\circ} \mathrm{C}$. Absorbance was measured at $450 \mathrm{~nm}$ with a microplate reader. The mean optical density (OD) of 4 wells in each group was used to calculate cell viability as follows:

Cell viability $(\%)=\left(\mathrm{OD}_{\text {treatment group }} / \mathrm{OD}_{\text {control group }}\right) \times 100$

Experiments were performed in triplicate.

Measurement of intracellular ROS: The DCF-DA method was used to detect the level of intracellular ROS. H9c2 cells were seeded on culture slides $\left(5 \times 10^{5}\right.$ cells/well $)$ for 24 hours and then the $\mathrm{CoCl}_{2}$-induced cell injury protocol was performed. CsA $(10,30$, and $50 \mathrm{ng} / \mathrm{mL})$ was added to the plates. The cells were incubated for an additional 24 hours at $37^{\circ} \mathrm{C}$. After the addition of $25 \mu \mathrm{M}$ of DCF-DA solution for 10 minutes, the fluorescence of DCF was detected using a fluorescence-activated cell sorting (FACS) caliber.

LDH, MDA, SOD, GSH, and CAT assays: LDH, MDA, SOD, $\mathrm{GSH}$, and CAT levels were measured using commercial kits, according to the manufacturer's protocol.

Hoechst 33342/PI assay: Cell apoptosis was analyzed by staining with Hoechst 33342/PI staining. H9c2 cells were collected, washed in PBS, resuspended in $0.8-1 \mathrm{~mL}$ of cell staining buffer containing $5 \mu \mathrm{L}$ of Hoechst 33342 and $5 \mu \mathrm{L}$ of PI incubated for $20-30$ minutes at $4{ }^{\circ} \mathrm{C}$ in the dark, washed in PBS, and then smeared on slides. The red fluorescence and the blue fluorescence were observed under a fluorescence microscope.

Measurement of mitochondrial membrane potential: A JC-1 fluorescent, lipophilic, and cationic probe was used to measure the mitochondrial membrane potential $(\Delta \psi \mathrm{m})$ of $\mathrm{H} 9 \mathrm{c} 2$ cells according to the manufacturer's protocol. H9c2 cells were plated in 96-well plates at a density of 5000 cells/well. When the cells had grown to $70-80 \%$ confluence, $\mathrm{CoCl}_{2}(700 \mu \mathrm{M})$ was added. The cells were then incubated with JC-1 staining solution for 20 minutes at $37^{\circ} \mathrm{C}$. The fluorescence was detected with a FACS caliber. The wavelengths of excitation and emission were 490 and $535 \mathrm{~nm}$ for detection of the monomeric form of JC-1. Wavelengths of 525 and $590 \mathrm{~nm}$ were used to detect aggregation of JC-1. The ratio of 'red' to 'green' fluorescence represented the $\Delta \psi \mathrm{m}$ of $\mathrm{H} 9 \mathrm{c} 2$ cells.

Western blot analysis: H9c2 cells were homogenized in RIPA lysis buffer containing protease inhibitor cocktail. Cytosolic proteins were isolated using a Cytosol Fractionation Kit (Abcam) according to the manufacturer's protocol. Total protein in the cell lysate was quantified using the BCA protein assay kit and size separated by $12 \%$ SDS-PAGE and electrotransferred onto a nitrocellulose membrane. Blots were incubated with antibodies against $\mathrm{Bax}, \mathrm{Bcl}-2$, cleaved caspase-9, caspase-9, cleaved caspase-3, caspase-3, cyto-c, p-p38, p38, p-ERK1/2, ERK1/2, p-JNK1/2, JNK1/2, and $\beta$-actin. Goat anti-rabbit IgG and goat anti-mouse IgG were added and the blots were devel- oped with an ECL plus kit (Abcam).

Statistical analyses: All data are presented as the mean \pm SEM. For multiple comparisons, the statistical analysis was performed using one-way ANOVA followed by Tukey's multiple comparison test. A $P<0.05$ was considered significant.

\section{RESUlts}

Effects of $\mathrm{CsA}$ on $\mathrm{CoCl}_{2}$-induced cytotoxicity: As shown in Figure $1 \mathrm{~A}$, the treatment of $\mathrm{H} 9 \mathrm{c} 2$ cells with $\mathrm{CoCl}_{2}$ (400-900 $\mu \mathrm{M})$ for 24 hours reduced cell viability in a concentration-dependent manner. The choice of $700 \mu \mathrm{M}$ for the concentration of $\mathrm{CoCl}_{2}$ applied to all the experiments was based on the CCK8 assay of survival in the $\mathrm{H} 9 \mathrm{c} 2$ cells. At this concentration, nearly $50 \%$ of the $\mathrm{CoCl}_{2}$-treated cells died within 24 hours. Other $\mathrm{H} 9 \mathrm{c} 2$ cells were treated with various concentrations of CsA alone for 24 hours. Cell viability was not significantly changed when cells were treated with CsA at concentrations ranging from $10 \mathrm{ng} / \mathrm{mL}$ to $50 \mathrm{ng} / \mathrm{mL}$, whereas CsA at concentrations of $60-70 \mu \mathrm{g} / \mathrm{mL}$ induced cell viability reduction (Figure 1B). H9c2 cells treated with CsA $(10,30$, and $50 \mu \mathrm{g} / \mathrm{mL})$ for 24 hours had significantly inhibited $\mathrm{CoCl}_{2}$-induced cytotoxicity and enhanced cell viability in a dose-dependent manner (Figure 1C). Cell apoptosis percentage in $\mathrm{H} 9 \mathrm{c} 2$ cells treated with $\mathrm{CoCl}_{2}$ was determined using the Hoechst 33342/PI method. Exposure of cells to $700 \mu \mathrm{M} \mathrm{CoCl}_{2}$ for 24 hours increased the percentage of apoptotic $\mathrm{H} 9 \mathrm{c} 2$ cells. The $\mathrm{CoCl}_{2}$-induced increase in the percentage of apoptotic $\mathrm{H} 9 \mathrm{c} 2$ cells was reversed by treatment with CsA, revealing the cytoprotective effect of CsA against chemical hypoxia-induced apoptosis (Figures 1D and D'). The results also suggested that CsA effectively reduced LDH leakage induced by $\mathrm{CoCl}_{2}$ (Figure 1E). These results suggest that $\mathrm{CsA}$ could protect $\mathrm{H} 9 \mathrm{c} 2$ cells against $\mathrm{CoCl}_{2}$ induced cytotoxicity.

Effects of CsA on $\mathbf{C o C l}_{2}$-induced ROS generation: The involvement of ROS in the $\mathrm{CoCl}_{2}$-induced apoptosis of $\mathrm{H} 9 \mathrm{c} 2$ cells was evaluated by measuring the level of ROS production. After $\mathrm{H} 9 \mathrm{c} 2$ cells had been treated with $700 \mu \mathrm{M} \mathrm{CoCl}_{2}$ for 24 hours, intracellular ROS levels increased compared with the control level. However, treatment with CsA decreased intracellular ROS levels, further demonstrating the antioxidant effects of CsA (Figures 2A and 2A').

Effects of $\mathrm{CsA}$ on $\mathrm{CoCl}_{2}$-induced changes in MDA concentration, SOD activity, GSH production, and CAT activity in H9c2 cells: Treatment of $\mathrm{H} 9 \mathrm{c} 2$ cells with $\mathrm{CoCl}_{2}$ significantly increased the MDA concentration and reduced SOD activity, GSH production, and CAT activity. The oxidative abnormalities were clearly ameliorated by CsA treatment, as manifested by the significant reduction in MDA concentration and the increases in SOD activity, GSH production, and CAT activity (Figures 2B, 2C, 2D, and 2E).

Effects of $\mathbf{C s A}$ on $\mathbf{C o C l}_{2}$-induced mitochondrial abnormalities: The $\Delta \psi \mathrm{m}$ disruption is believed to be a common early event of apoptosis prompted by a variety of stimuli, including hypoxia. As shown in Figure 3A, exposure of cells to $\mathrm{CoCl}_{2}$ for 24 hours induced a significant loss of $\Delta \psi \mathrm{m}$ in $\mathrm{H} 9 \mathrm{c} 2$ cells. Interestingly, treatment with CsA markedly attenuated the loss of $\Delta \psi \mathrm{m}$. These results suggest that CsA protects $\mathrm{H} 9 \mathrm{c} 2$ cells against $\mathrm{CoCl}_{2}$-induced loss of $\Delta \psi \mathrm{m}$ by inhibiting ROS overproduction. $\mathrm{CoCl}_{2}$ treatment resulted in a significantly in- 


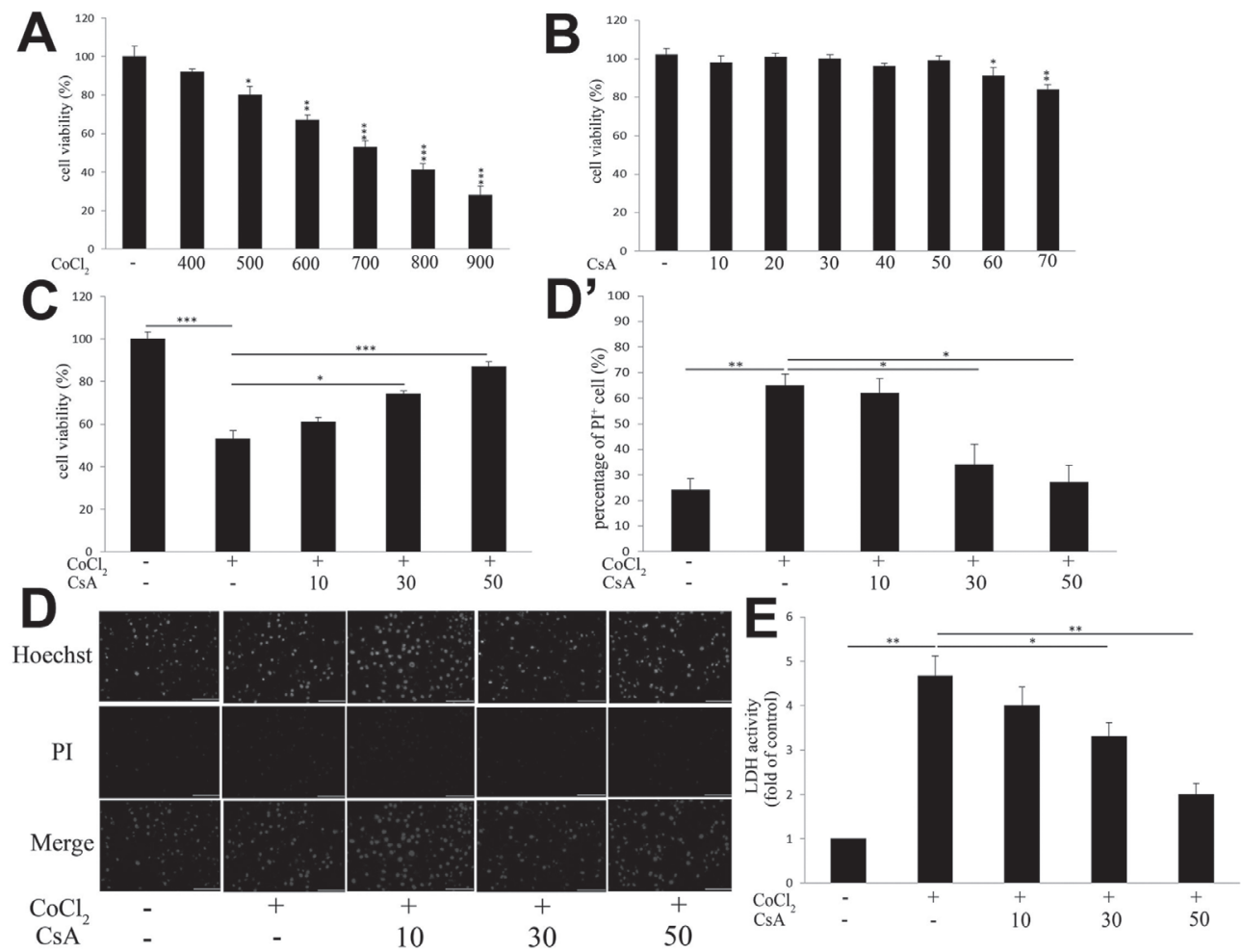

Figure 1. Effects of $\mathrm{CsA}$ on $\mathrm{CoCl}_{2}$-induced cell death in $\mathrm{H} 9 \mathrm{c} 2$ cells. A: $\mathrm{H} 9 \mathrm{c} 2$ cells were exposed to different concentrations of $\mathrm{CoCl}_{2}$ for 24 hours and cell viability was analyzed by CCK- 8 assay. Results are expressed as the mean \pm SEM. $n=$ 3. ${ }^{*} P<0.05,{ }^{*{ }^{*}} P<0.01,{ }^{* * * *} P<0.001$ versus control. B: H9c2 cells were incubated with CsA alone at indicated concentrations for 24 hours and cell viability was analyzed by CCK-8 assay. Results are expressed as the mean \pm SEM. $n=3 .{ }^{*} P<$ $0.05,{ }^{* *} P<0.01,{ }^{* * *} P<0.001$ versus control. C: H9c2 cells were incubated with CsA $(10,30$, and $50 \mu \mathrm{g} / \mathrm{mL})$ for 24 hours after $\mathrm{CoCl}_{2}$-induced injury and cell viability was analyzed by CCK- 8 assay. Results are expressed as the mean \pm SEM. $n=3$. ${ }^{*} \mathrm{P}<0.05,{ }^{2 * *} \mathrm{P}<0.01,{ }^{* * *} \mathrm{P}<0.001$. D: Effects of $\mathrm{CsA}$ on $\mathrm{CoCl}_{2}$-induced apoptosis in $\mathrm{H} 9 \mathrm{c} 2$ cells. Cell apoptosis rate was determined with a fluorescence microscope after staining with Hoechst 33342/PI. Scale bar $=100 \mu \mathrm{m}$. D': Representative percentages of $\mathrm{PI}^{+}$are shown. Each bar represents the mean \pm SEM. $n=3 ;{ }^{*} P<0.05,{ }^{* *} P<0.01,{ }^{* * *} P<0.001$. E: LDH assay. Cells were incubated with CsA at the indicated concentrations for 24 hours after $\mathrm{CoCl}_{2}$-induced injury and $\mathrm{LDH}$ results are shown. Each bar represents the mean \pm SEM. $n=3 ;{ }^{*} P<0.05,{ }^{* *} P<0.01,{ }^{* * * *} P<0.001$.

creased cytosolic cyto-c protein expression. Treatment with CsA reduced the level of cytosolic cyto-c in a dose-dependent manner. Both the p38 inhibitor SB203580 and the ERK inhibitor U0126 further reduced the level of cytosolic cyto-c. The JNK inhibitor SP600125 did not have a significant effect (Figure 3B).

Effects of $\mathrm{CsA}$ on $\mathrm{CoCl}_{2}$-induced upregulation of Bax/Bcl-2, clcasp-9/casp-9, and cl-casp-3/casp-3 ratios: The results of the Western blot analysis showed that treatment with $700 \mu \mathrm{M}$ $\mathrm{CoCl}_{2}$ for 24 hours markedly up-regulated the $\mathrm{Bax} / \mathrm{Bcl}-2$, clcasp-9/casp-9, and cl-casp-3/casp-3 ratios in H9c2 cells. Importantly, treatment with CsA significantly inhibited the increases in the Bax/Bcl-2, cl-casp-9/casp-9, and cl-casp-3/casp3 ratios. SB203580 and U0126 further reduced the ratios of Bax/Bcl-2, cl-casp-9/casp-9, and cl-casp-3/casp-3. SP600125 did not attenuate these effects (Figure 3C).

CsA protects $\mathrm{H} 9 \mathrm{c} 2$ cells against $\mathrm{CoCl}_{2}$-induced hypoxic injury by suppressing MAPK signaling pathways: The phosphorylations of p38, ERK1/2, and JNK1/2 were significantly increased in $\mathrm{H} 9 \mathrm{c} 2$ cells after $\mathrm{CoCl}_{2}$-induced injury. CsA significantly decreased the phosphorylation of p38 and ERK1/2 in H9c2 cells in a dose-dependent manner. In contrast, CsA did not affect the phosphorylation of JNK1/2 after $\mathrm{CoCl}_{2}$-induced injury (Figure 4A). These results suggested that CsA protects $\mathrm{H} 9 \mathrm{c} 2$ cells against $\mathrm{CoCl}_{2}$-induced injury by suppressing MAPK signaling pathways.

\section{Discussion}

Recently, CsA has been reported to be capable of modulating many pathological processes in the body. CsA is one of the highly effective drugs in preventing brain ischemic damage. ${ }^{7)}$ CsA is also believed to be an important pathological mediator capable of regulating myocardial ischemic damage. This study investigated whether CsA can protect $\mathrm{H} 9 \mathrm{c} 2$ cells from hypoxic/ischemic injury in vitro. The results showed that CsA inhibited $\mathrm{CoCl}_{2}$-induced apoptosis in $\mathrm{H} 9 \mathrm{c} 2$ cells by regulating ROS-initiated MAPK signaling pathways.

$\mathrm{CoCl}_{2}$-treated $\mathrm{H} 9 \mathrm{c} 2$ cells may serve as a simple and useful in vitro model for exploring the mechanisms underlying the hypoxia-linked damage in cardiac cells because H9c2 cells can exhibit electrophysiological and biochemical properties of cardiac tissues. ${ }^{8)}$ The present study evaluated the potential mecha- 


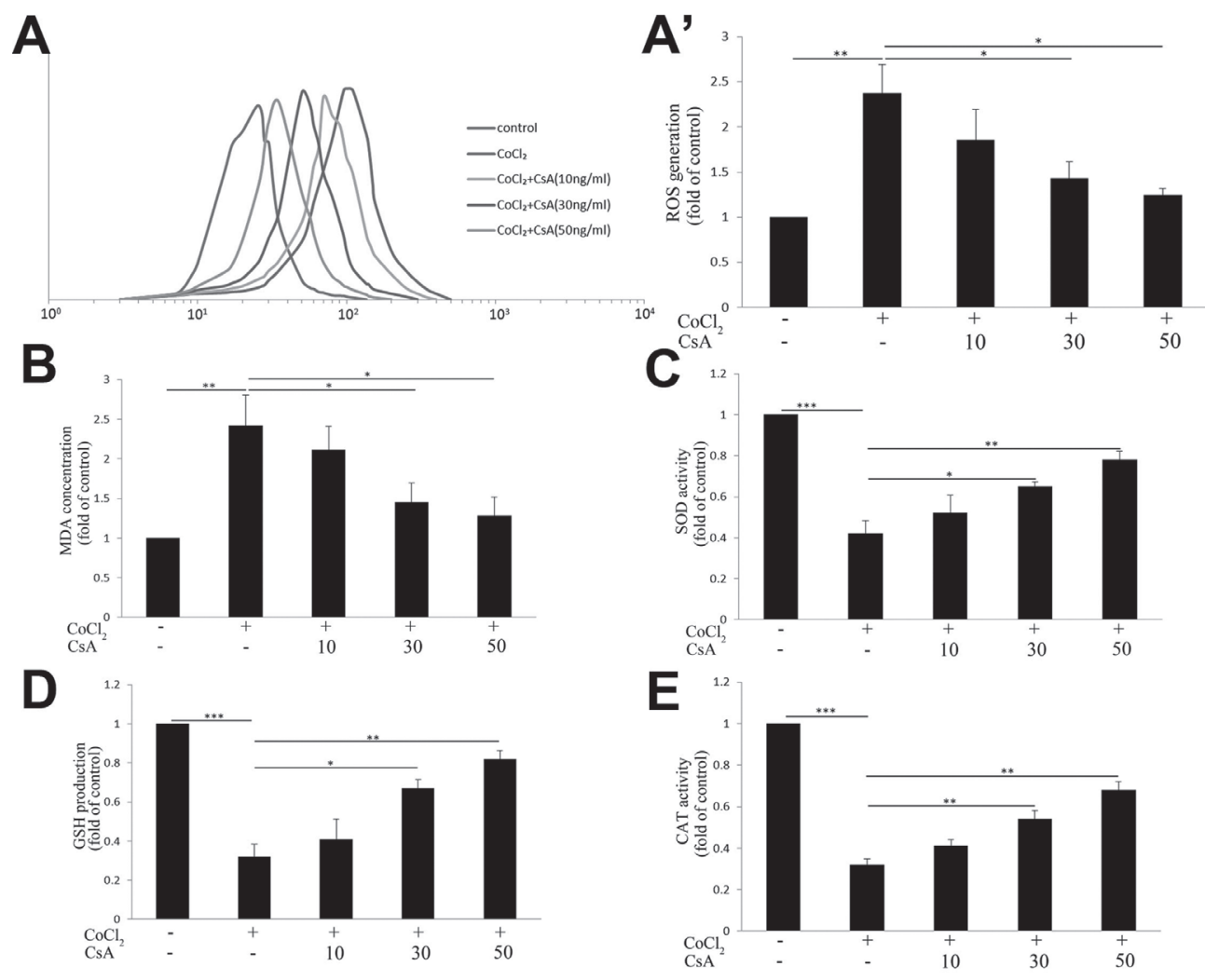

Figure 2. Effects of CsA on ROS production, MDA concentration, SOD activity, GSH production, and CAT activity in H9c2 cells. A: ROS generation was determined using a fluorescence probe, DCFH-DA. Representative pictures were taken by FACS. A': Flow cytometric analysis of ROS fluorescence in each group. B: MDA assay. C: SOD assay. D: GSH assay. E: CAT assay. Each bar represents the mean \pm SEM. $n=3 ;{ }^{*} P<0.05,{ }^{* *} P<0.01,{ }^{* * * *} P<0.001$.

nisms of CsA-mediated cardioprotection with the use of an in vitro chemical hypoxia-induced injury model. This study also demonstrated that $\mathrm{CoCl}_{2}$, a chemical hypoxia-mimetic agent, significantly suppressed cell viability and induced apoptosis in H9c2 cells.

According to the results of this study, CsA reduced oxygen demand, thereby protecting $\mathrm{H} 9 \mathrm{c} 2$ cells from $\mathrm{CoCl}_{2}$-induced injury. CsA also protected $\mathrm{H} 9 \mathrm{c} 2$ cells against $\mathrm{CoCl}_{2}$-induced injury, enhancing cell viability and reducing the percentage of apoptotic cells. The increased LDH activity in a culture medium in generally known to correspond to the degree of cell death. ${ }^{9}$ We assessed $\mathrm{CoCl}_{2}$-induced $\mathrm{H} 9 \mathrm{c} 2$ cell death and cardiotoxicity through LDH assays and confirmed that $\mathrm{CoCl}_{2}$ significantly increased LDH release. However, treatment with different concentrations of CsA markedly attenuated the increase in LDH release. Hypoxia/ischemia induced oxidative stress injuries by scavenging ROS and lipid peroxidation production of MDA. ${ }^{10)}$ SOD is one of the principal enzymes that scavenge free radicals. ${ }^{11)} \mathrm{GSH}$, which is a major cellular antioxidant, is not only the immediate donor of electrons to neutralize $\mathrm{H}_{2} \mathrm{O}_{2}$ and lipoperoxide, but also a scavenger of oxygen and nitrogen-based free radicals. ${ }^{12)} \mathrm{CAT}$ is a defense molecule against toxic oxygen metabolites. ${ }^{13)} \mathrm{CoCl}_{2}$ significantly enhanced MDA concentration and inhibited SOD activity, GSH production, and CAT activity. By contrast, CsA prevented $\mathrm{CoCl}_{2}$-induced cell injuries, decreased MDA levels, and increased SOD, GSH, and CAT levels. The present study pro- vides novel evidence to demonstrate that $\mathrm{CoCl}_{2}$, a chemical hypoxia mimetic agent, damages $\mathrm{H} 9 \mathrm{c} 2$ cells by increasing ROS production and MDA concentration and suppressing SOD activity, GSH production, and CAT activity. Our previous studies showed that CsA protected $\mathrm{H} 9 \mathrm{c} 2$ cells from oxidative damage by reversing these effects.

The results of a recent study indicated that $\mathrm{CoCl}_{2}$-induced apoptosis of $\mathrm{H} 9 \mathrm{c} 2$ cells might be associated with the mitochondrial apoptotic pathway. ${ }^{14)}$ The mitochondria-dependent apoptotic pathway may be activated under hypoxic/ischemic conditions by increasing ROS production, disrupting mitochondrial membrane potential, releasing cyto-c from the damaged mitochondria to the cytosol, and activating caspase-9 and caspase-3, which subsequently contribute to apoptotic cell death. Caspase-9 is an initiator of apoptosis and caspase- 3 is an effector of apoptosis, both of which regulate cell apoptosis. ${ }^{15)}$ Pro-apoptotic protein Bax and anti-apoptotic protein Bcl2 on the outer mitochondrial membrane could regulate membrane permeability and mitochondrial integrity, thereby affecting the release of cyto-c from the mitochondrion and catalyzing mitochondria-dependent caspase- 9 and caspase- 3 activation. ${ }^{16)}$ To explore whether CsA prevented the $\mathrm{CoCl}_{2}$-induced apoptosis of $\mathrm{H} 9 \mathrm{c} 2$ cells by inhibiting the factors involved in the mitochondrial apoptotic pathway, we evaluated the effect of $\mathrm{CoCl}_{2}$ on ROS production. Intracellular ROS levels increased in $\mathrm{CoCl}_{2}$-treated $\mathrm{H} 9 \mathrm{c} 2$ cells, and this increase was suppressed by $\mathrm{CsA}$. These results indicate that ROS production 

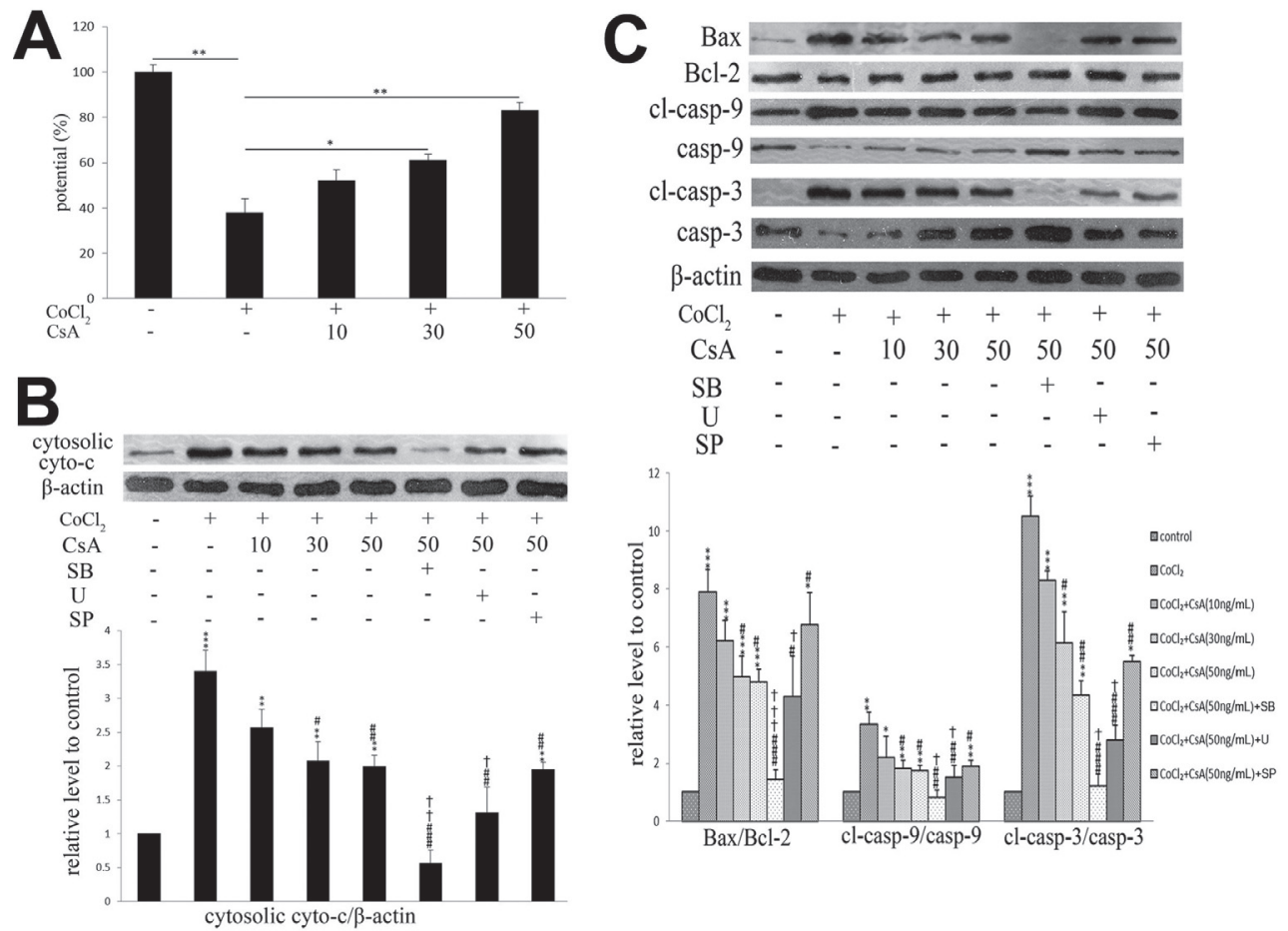

Figure 3. CsA against $\mathrm{CoCl}_{2}$-induced mitochondrial abnormalities and cell apoptosis in $\mathrm{H} 9 \mathrm{c} 2$ cells. A: Effect of CsA on $\Delta \psi \mathrm{m}$ determined using JC-1. $\Delta \psi \mathrm{m}$ was measured by FACS. B: Determination of cyto-c release by Western blot. C: The ratios of Bax/Bcl-2, cl-casp-9/casp-9, and cl-casp-3/casp-3 were analyzed by Western blot. Each bar represents the mean \pm SEM. $n=3 ;{ }^{*} P<0.05,{ }^{* *} P<0.01,{ }^{* * * *} P<0.001$ versus control. ${ }^{\#} P<0.05,{ }^{, \#} P<0.01,{ }^{\# \# !} P<0.001$ versus $\mathrm{CoCl}_{2}$-induced injury group. ${ }^{\dagger} P<0.05,{ }^{\dagger} P<0.01,{ }^{\dagger \dagger} P<0.001$ versus $50 \mathrm{ng} / \mathrm{mL}$ CsA -treated group.

may be involved in $\mathrm{CoCl}_{2}$-induced apoptosis of $\mathrm{H} 9 \mathrm{c} 2$ cells and CsA is capable of scavenging ROS, which could be one of the mechanisms underlying the protective effects of CsA against $\mathrm{CoCl}_{2}$-induced injury in $\mathrm{H} 9 \mathrm{c} 2$ cells. These results suggest that $\mathrm{CoCl}_{2}$ induces the apoptosis of $\mathrm{H} 9 \mathrm{c} 2$ cells via the mitochondrial apoptotic pathway. The results also suggest that CsA treatment reversed the Bax/Bcl-2, cl-casp-9/casp-9, and cl-casp-3/ casp-3 ratios promoted by $\mathrm{CoCl}_{2}$ exposure. This finding correlates well with the blockage of cyto-c release and inhibition of $\Delta \psi \mathrm{m}$ by CsA treatment. We demonstrated that CsA protects $\mathrm{H} 9 \mathrm{c} 2$ cells against $\mathrm{CoCl}_{2}$-induced injury by suppressing oxidative stress and preserving mitochondrial function. In this study, CsA was involved in myocardial injury initiated by $\mathrm{CoCl}_{2}$-induced injury. Furthermore, CsA significantly decreased the ratios of Bax/Bcl-2, cl-casp-9/casp-9, and cl-casp-3/casp-3, as well as blocked cyto-c release from the mitochondrion; such a release may be related to MAPK signaling pathways.

MAPK signaling pathways are considered mediators of cardiac ischemia/reperfusion injuries. ${ }^{17)}$ Oxidative stress can result in the activation of MAPK cascade in cardiac ischemia/ reperfusion injury. ${ }^{18)}$ The activation of p38 and ERK during cardiac ischemia/reperfusion injury is associated with mitochondrial dysfunction. ${ }^{19)}$ The mitochondria are important and central mediators of death. Bax and Bcl-2 in the outer mitochondrial membrane could result in cell apoptosis and the activation of caspase- 9 and caspase- $3 .^{20)}$ In our study, CsA inhibited p38 and ERK MAPK activation but did not affect the increased JNK expression. These results suggest that the p38 and ERK MAPK pathways could be involved in the reduced
$\mathrm{H} 9 \mathrm{c} 2 \mathrm{CoCl}_{2}$-induced injury effects of CsA. CsA protects $\mathrm{H} 9 \mathrm{c} 2$ cell death by inhibiting p38 and ERK MAPK pathways.

ROS can activate MAPK signaling pathways, including p38, ERK, and JNK, which have pivotal roles in cardiovascular diseases. The activation of MAPK signaling pathways is linked to ROS generation and the progression of cell apoptosis. Our study showed that $\mathrm{CoCl}_{2}$-induced hypoxic injury significantly enhanced the expression levels of p-p38, p-ERK, and pJNK MAPK, indicating the activation of MAPK by ROS. CsA protects $\mathrm{H} 9 \mathrm{c} 2$ cells by suppressing the hypoxic injury-induced activities of p38 and ERK phosphorylation but does not affect the increased JNK phosphorylation expression. Indeed, in this study, CsA inhibited p38 and ERK MAPK but did not affect the increased JNK expression. H9c2 cells were pretreated with $15 \mu \mathrm{M}$ SB203580 (a selective inhibitor of p38 MAPK), $15 \mu \mathrm{M}$ U0126 (a selective inhibitor of ERK MAPK), and $15 \mu \mathrm{M}$ SP600125 (a selective inhibitor of JNK MAPK) before exposure to $\mathrm{CoCl}_{2}$-induced hypoxic injury. The activation of $\mathrm{p} 38$ and ERK MAPK significantly attenuated the myocardial protective effects of CsA on hypoxic injury-induced death in $\mathrm{H} 9 \mathrm{c} 2$ cells because the factors (p38 and ERK) inhibited by CsA were inhibited in the presence of SB203580 or U0126 pharmacological inhibitors. However, SP600125 did not affect the growth of $\mathrm{H} 9 \mathrm{c} 2$ cells. CsA can have a myocardial protection effect on $\mathrm{CoCl}_{2}$-induced hypoxic injury through inhibition of the ROS/MAPK pathway.

The endogenous defense system, primarily the antioxidant enzyme system SOD, is critical to attenuate the injury induced by hypoxia. CsA enhanced the level of the antioxidase 


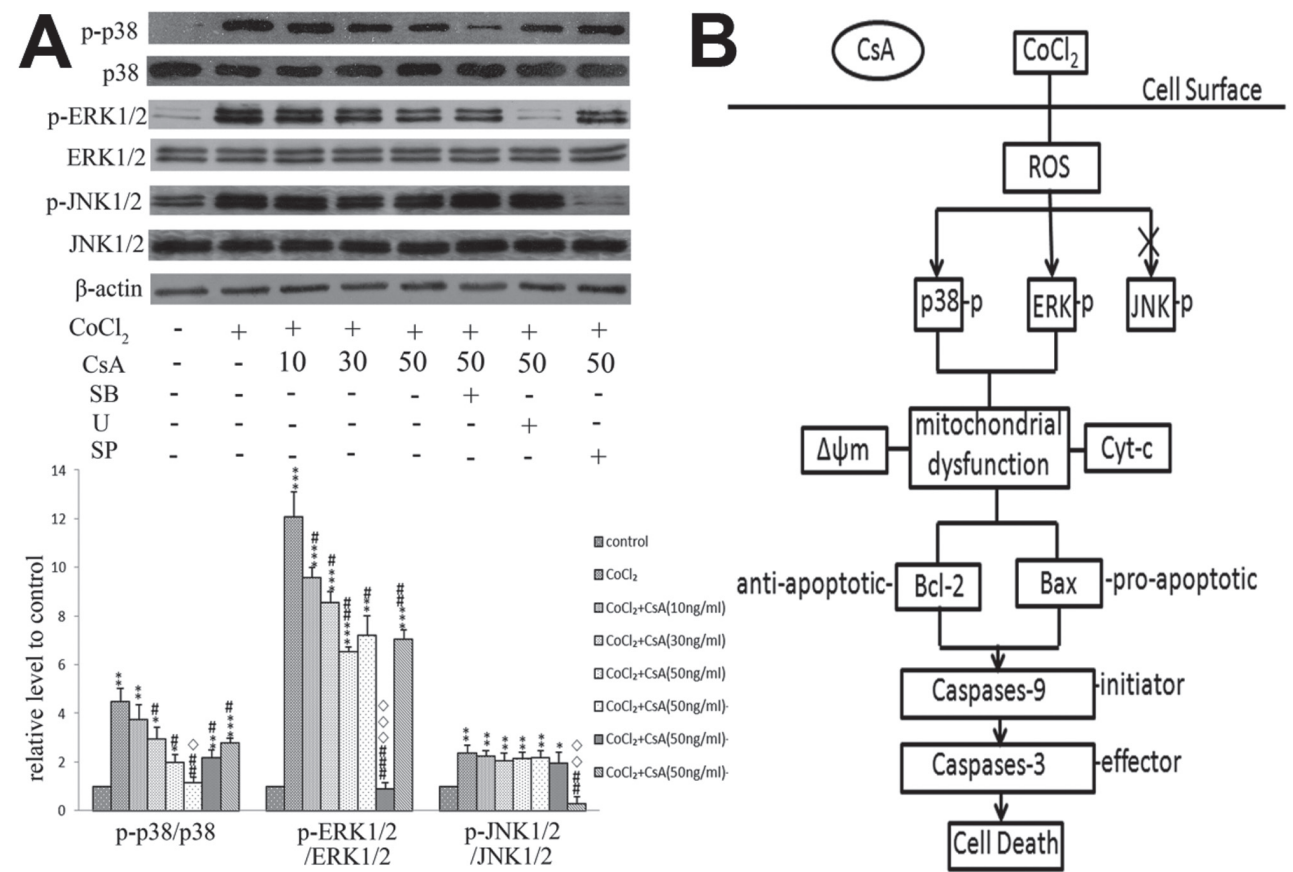

Figure 4. CsA against $\mathrm{CoCl}_{2}$-induced injury in $\mathrm{H} 9 \mathrm{c} 2$ cells via inhibition of MAPK signaling pathways. A: The ratios of p-p38/p38, p-ERK1/2/ERK1/2, and p-JNK1/2/JNK1/2 were analyzed by Western blot. Each bar represents the mean \pm SEM. $n=3 ;{ }^{*} P<0.05,{ }^{* *} P<0.01,{ }^{* * * *} P<0.001$ versus control. ${ }^{\#} P<0.05,{ }^{\# \#} P<0.01,{ }^{\# \prime \prime \prime} P<0.001$ versus $\mathrm{CoCl}_{2}$-induced injury group. ${ }^{\dagger} P<0.05,{ }^{\dagger} P<0.01,{ }^{\dagger} P<0.001$ versus $50 \mathrm{ng} / \mathrm{mL}$ CsA -treated group. $\mathbf{B}$ : $\mathrm{CoCl}_{2}$-induced $\mathrm{H} 9 \mathrm{c} 2$ cell death is prevented by $\mathrm{CsA}$ by inhibiting downstream MAPK signaling pathway activation. $\mathrm{CoCl}_{2}$ can initiate mitochondrial apoptotic processes, including decreased $\Delta \psi \mathrm{m}$; release of cyto-c; and imbalance of Bax/Bcl-2, cl-casp-9/casp-9, and cl-casp-3/casp-3 ratios. These results are related to the downregulation of $\mathrm{p} 38$ and ERK MAPK.

activity of SOD with respect to the $\mathrm{CoCl}_{2}$-induced hypoxic injury group. Thus, we suppose that treatment with CsA can increase SOD activities to reduce hypoxic injury. Extensive research has shown that ROS generation may result in apoptosis during hypoxic injury and reduced ROS generation can suppress hypoxic injury via antioxidants and antioxidative enzymes, such as SOD. SOD is a powerful antioxidant that catalyzes redox reactions by converting superoxide radicals into hydrogen peroxide and oxygen. We provided clear evidence that CsA treatment can protect from apoptosis by inhibiting the p38 and ERK MAPK pathways. Furthermore, we found a positive interaction between ROS, p38, and ERK MAPK activation and SOD activity reduction: CsA treatment decreased ROS generation and suppressed the p38 and ERK MAPK pathways and increased SOD activities, indicating that CsA has partial antioxidative activity by modulating the ROS-induced $\mathrm{p} 38$ and ERK MAPK pathways.

Two major limitations of the present study need to be acknowledged and addressed. First, we attempted to demonstrate the cardioprotection effects of CsA by performing the study on a cell line but not on a system that is more relevant to an in vivo situation. Second, in this study, we used the H9c2 cell line (rat cardiomyocyte cell line) and not real myocardial cells, although H9c2 cells do display some myocardial functions. More experiments must be conducted using an animal model or real myocardial cells, particularly primary myocardial cells, in future studies to verify the cardioprotection effect of CsA.

In conclusion, our results indicate that $\mathrm{CsA}$ may protect
H9c2 cells against chemical hypoxia-induced injury by suppressing the p38 and ERK MAPK signaling pathways (summarized in Figure 4B). Thus, CsA is potentially a novel therapeutic target for the treatment of cardiac ischemia/reperfusion injury.

\section{Disclosures}

Conflict of interest: There is no conflict of interest to report for any author.

Ethical standards: The study complies with current ethical standards.

\section{REFERENCES}

1. Kaminska B, Gaweda-Walerych K, Zawadzka M. Molecular mechanisms of neuroprotective action of immunosuppressants facts and hypotheses. J Cell Mol Med 2004; 8: 45-58. (Review)

2. Takeishi Y. Biomarkers in heart failure. Int Heart J 2014; 55: 47481. (Review)

3. Kinugawa S, Takada S, Matsushima S, Okita K, Tsutsui H. Skeletal muscle abnormalities in heart failure. Int Heart J 2015; 56: 47584. (Review)

4. Guo L, Yang X, Lin X, et al. Silencing of Id2 attenuates hypoxia/ ischemia-induced neuronal injury via inhibition of neuronal apoptosis. Behav Brain Res 2015; 292: 528-36.

5. Chen J, Wang W, Zhang Q, et al. Low molecular weight fucoidan 
against renal ischemia-reperfusion injury via inhibition of the MAPK signaling pathway. PLoS One 2013; 8: e56224.

6. Ekhterae D, Lin Z, Lundberg MS, Crow MT, Brosius FC 3rd, Núñez G. ARC inhibits cytochrome c release from mitochondria and protects against hypoxia-induced apoptosis in heart-derived H9c2 cells. Circ Res 1999; 85: e70-7.

7. Li PA, He QP, Siesjö BK. Effects of intracarotid arterial injection of cyclosporin A and spontaneous hypothermia on brain damage incurred after a long period of global ischemia. Brain Res 2001; 890: 306-13.

8. Hescheler J, Meyer R, Plant S, Krautwurst D, Rosenthal W, Schultz G. Morphological, biochemical, and electrophysiological characterization of a clonal cell $(\mathrm{H} 9 \mathrm{c} 2)$ line from rat heart. Circ Res 1991; 69: 1476-86.

9. Weber NC, Riedemann I, Smit KF, et al. Plasma from human volunteers subjected to remote ischemic preconditioning protects human endothelial cells from hypoxia-induced cell damage. Basic Res Cardiol 2015; 110: 17

10. Chang ST, Chung CM, Chu CM, et al. Platelet glycoprotein IIb/ IIIa inhibitor tirofiban ameliorates cardiac reperfusion injury. Int Heart J 2015; 56: 335-40.

11. Liu J, Hou J, Xia ZY, et al. Recombinant PTD-Cu/Zn SOD attenuates hypoxia-reoxygenation injury in cardiomyocytes. Free Radic Res 2013; 47: 386-93.

12. Leichtweis S, Ji LL. Glutathione deficiency intensifies ischaemiareperfusion induced cardiac dysfunction and oxidative stress. Acta Physiol Scand 2001; 172: 1-10.

13. Ferrari R, Ceconi C, Curello S, Cargnoni A, Condorelli E, Raddi- no R. Role of oxygen in myocardial ischaemic and reperfusion damage: effect of alpha-tocopherol. Acta Vitaminol Enzymol 1985; 7: 61-70.

14. Xu ZW, Chen X, Jin XH, et al. SILAC-based proteomic analysis reveals that salidroside antagonizes cobalt chloride-induced hypoxic effects by restoring the tricarboxylic acid cycle in cardiomyocytes. J Proteomics 2016; 130: 211-20.

15. Cain K. Chemical-induced apoptosis: formation of the Apaf-1 apoptosome. Drug Metab Rev 2003; 35: 337-63. (Review)

16. Cui C, Cui N, Wang P, Song S, Liang H, Ji A. Sulfated Polysaccharide isolated from the sea cucumber Stichopus japonicus against PC12 hypoxia/reoxygenation injury by inhibition of the MAPK signaling pathway. Cell Mol Neurobiol 2015; 35: 108192.

17. Sun L, Chen C, Jiang B, et al. Grb2-associated binder 1 is essential for cardioprotection against ischemia/reperfusion injury. Basic Res Cardiol 2014; 109: 420.

18. Datta NS, Chukkapalli S, Vengalil N, Zhan E, Przyklenk K, Lasley R. Parathyroid hormone-related peptide protects cardiomyocytes from oxidative stress-induced cell death: First evidence of a novel endocrine-cardiovascular interaction. Biochem Biophys Res Commun 2015; 468: 202-7.

19. Javadov S, Jang S, Agostini B, Crosstalk between mitogen-activated protein kinases and mitochondria in cardiac diseases: therapeutic perspectives. Pharmacol Ther 2014; 144: 202-25. (Review)

20. Karch J, Molkentin JD. Regulated necrotic cell death: the passive aggressive side of Bax and Bak. Circ Res 2015; 116: 1800-9. 